\title{
BIOSSEGURANÇA E ACIDENTES DE TRABALHO COM PÉRFURO-CORTANTES ENTRE OS PROFISSIONAIS DE ENFERMAGEM DE HOSPITAL UNIVERSITÁRIO DE FORTALEZA-CE
}

Débora Conceição Rodrigues Paulino ${ }^{1}$, Marcos Venícios Oliveira Lopes², Isaura Letícia Tavares Palmeira Rolim³

RESUMO: Pesquisa documental exploratória, realizada em hospital público de Fortaleza em 2005. Objetivos: caracterizar os acidentes de trabalho ocorridos entre profissionais de saúde; analisar a frequêencia com que ocorrem acidentes de trabalho com dispositivos pérfuro-cortantes entre a equipe de Enfermagem notificados na Ficha de Notificação de Acidentes e identificar quais os fatores contribuintes para sua ocorrência entre os trabalhadores de Enfermagem. Utilizou-se informações contidas na Ficha de Notificação. A maior parte dos acidentes (54,8\%) aconteceu entre os auxiliares de Enfermagem. O local em que mais houve acidentes foi no quarto do paciente, seguido do Centro Cirúrgico. O reencape de agulhas causou 27,5\% dos acidentes notificados. Os ferimentos variaram entre superficial e moderado, com freqüência de 48,6\% cada um. O acidente de trabalho é uma circunstância grave que expõe o trabalhador a risco de infecção, possivelmente influenciado pela maneira como esses dispositivos são distribuídos de forma restrita ao posto de Enfermagem e pela sobrecarga de trabalho dos profissionais. É necessário implementar medidas que tornem as condições de trabalho mais seguras e investigar o que leva esses profissionais a fazerem-no e, planejar uma mudança de comportamento e melhores condições de trabalho.

PALAVRAS-CHAVE: Acidentes de trabalho; Exposição a agentes biológicos; Atividade de cuidado em saúde.

\section{BIOSAFETY AND OCCUPATIONAL ACCIDENTS WITH SHARP OBJECTS AMONG NURSING PROFESSIONALS AT A UNIVERSITY HOSPITAL IN FORTALEZA-CEARÁ/ BRAZIL}

ABSTRACT: Documental- exploratory research carried out at a public hospital in Fortaleza, Ceará State/ Brazil. Objectives: to feature occupational accidents occurred among nursing professionals; to analyze the frequency of these occupational accidents with sharp objects among the nursing team reported in the Accident Notification Card and to identify the contributing factors for their occurrence among nursing professionals. It was used the information reported in the Notification Card.. Most accidents (54.8\%) occurred among nursing aides. They mostly occurred in patients' rooms, followed by the Surgical Center. Needles recapping was responsible for $27.5 \%$ of the reported accidents. Wounds varied from superficial to moderate with frequency of $48.6 \%$ each one. Occupational accidents are serious circumstances exposing professionals to infection risk, possibly influenced by the way this material is restrictedly distributed to the nursing team as well as professionals' work overload. It is necessary to implement measures aiming at safer working conditions and investigate what leads these professionals to suffer occupational accidents, thus planning a change in their behavior as well as better working conditions.

KEYWORDS: Occupational accidents; Exposure to biological agents; Health care activity.

\section{BIOSEGURANZA Y DE ACCIDENTES DE TRABAJO ENTRE LOS PROFESIONALES DE ENFERMERÍA DEL HOSPITAL UNIVERSITARIO EN FORTALEZA-CE}

RESUMEN: Los objetivos considerados para este trabajo han sido: caracterizar accidentes entre los profesionales de Enfermería; analizar la frecuencia de los accidentes de trabajo con objetos perforantes cortantes ocurridos en el equipo de enfermería con registro en la ficha de notificación. Se buscó identificar a los factores que contribuyen a la incidencia de accidentes entre los trabajadores de enfermería. Esta investigación documental exploratoria fue hecha en el hospital público de Fortaleza, en abril de 2005, utilizando la ficha de notificación. La mayoría de los accidentes (54,8\%) ocurrió con los asistentes de enfermería. El lugar donde más se producen accidentes es en la habitación del paciente, seguida del centro quirúrgico. Agujas fueron responsables por $27,5 \%$ de los accidentes notificados. Las heridas han variado con frecuencia entre superficial y moderada: $48,6 \%$ cada uno de ellos. El accidente laboral es una grave circunstancia en que el trabajador se muestra en riesgo de infección. Esse riesgo es causado por la persistencia de los malos hábitos. Es necesario implementar medidas que vuelvan más seguras las condiciones de trabajo e investigar como y por que ocurre, así como planear un cambio de comportamiento y mejores condicines de trabajo.

PALABRAS CLAVE: Accidentes de trabajo; Exposición a agentes biológicos; Atención de la salud.

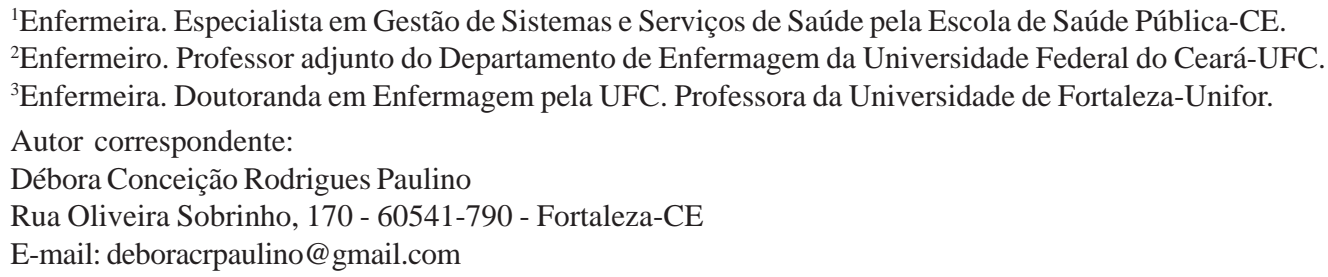

${ }^{1}$ Enfermeira. Especialista em Gestão de Sistemas e Serviços de Saúde pela Escola de Saúde Pública-CE. ${ }^{2}$ Enfermeiro. Professor adjunto do Departamento de Enfermagem da Universidade Federal do Ceará-UFC. ${ }^{3}$ Enfermeira. Doutoranda em Enfermagem pela UFC. Professora da Universidade de Fortaleza-Unifor.

Autor correspondente:

Débora Conceição Rodrigues Paulino

Rua Oliveira Sobrinho, 170 - 60541-790 - Fortaleza-CE

E-mail: deboracrpaulino@gmail.com

Recebido: 17/10/07 Aprovado: 19/09/08 


\section{INTRODUÇÃO}

A primeira forma de resguardar os trabalhadores em caso de acidentes de trabalho foi a instituição do seguro de acidentes de trabalho em 1919. Em 1923 a Lei Eloy Chaves instituiu as Caixas de Aposentadorias e Pensões (CAPs) como resposta aos movimentos populares urbanos que cobravam o controle das condições de trabalho que aconteciam de forma altamente predadora. Entretanto, o foco era a conseqüência, não a causa, já que não havia uma política de prevenção de agravos. Do início da década de 20 do século passado até os dias atuais a legislação evoluiu. Com a promulgação da Constituição de 1988 foi estabelecido um novo sistema de saúde, o Sistema Único de Saúde (SUS), que separou a saúde da previdência, sendo esta responsável pelas concessões e gerenciamento de aposentadorias, pensões e seguros de acidentes de trabalho ${ }^{(1)}$.

Acidente de trabalho é caracterizado como aquele que advém do exercício do trabalho provocando lesão corporal que pode levar à morte, perda ou diminuição (transitória ou permanente) da capacidade funcional. É classificado como típico quando ocorre no próprio local de trabalho ou como de trajeto quando ocorre na ida ou volta do trabalho ${ }^{(1)}$.

Cada profissão tem seus riscos inerentes à natureza e ao ambiente do seu trabalho, que podem causar acidentes ou doenças ocupacionais ${ }^{(3)}$. Os riscos podem ser classificados em reais, ou seja, riscos de responsabilidade do empregador, riscos supostos, quando se supõe que o trabalhador conhece suas causas, e riscos residuais, que são de responsabilidade do trabalhador ${ }^{(4)}$. Dessa forma, a redução dos riscos deve ser uma ação conjunta entre empregados e empregadores.

Entre os órgãos internacionais, o Center for Disease Control and Prevention (CDC) define trabalhador em saúde como toda pessoa (empregados, estudantes, atendentes de consultório, trabalhadores em saúde pública ou voluntários) que desempenha atividades que envolvem contato com pacientes ou com sangue ou com fluidos corporais de pacientes internados, em laboratório ou em vigilância sanitária ${ }^{(5)}$.

Os trabalhadores em saúde se expõem a riscos ergonômicos (relacionados ao desenho do local de trabalho e as posições adotadas durante a execução das tarefas), riscos físicos (relacionados a agentes físicos como temperatura, radiação), riscos químicos (medicações, substâncias desinfetantes), riscos psicológicos (intensidade do trabalho, o lidar com a dor e o sofrimento), riscos mecânicos (as lesões por pérfuro-cortantes, quedas, esmagamentos) e riscos biológicos ${ }^{(4,6)}$.

São os riscos biológicos os que causam maior preocupação para os trabalhadores da saúde, já que risco biológico é “a probabilidade de exposição ocupacional a agentes biológicos”(1) e a exposição ocupacional a agentes patogênicos implica uma possível infecção. Por isso, é necessário implementar medidas de biossegurança as quais se referem a um "instrumento de proteção à vida" que permite observar a complexidade dos processos de trabalho(7), ou seja, biossegurança é interdisciplinaridade e ação educativa que tem como objetivo a preservação da saúde dos seres humanos, dos animais e do ambiente.

Contudo o interesse pela exposição ocupacional dos trabalhadores da saúde a patógenos sangüíneos é recente, com maior preocupação após o surgimento da epidemia de aids a partir dos anos 80. Atualmente, o acidente de trabalho é uma emergência médica ${ }^{(1)} \mathrm{e}$ se configura como um problema relevante entre os profissionais de saúde, em especial a exposição ocupacional a esses patógenos por meio de acidente com pérfuro-cortantes.

Dentre esses microorganismo podemos destacar os vírus da imunodeficiência humana, da hepatite $\mathrm{B}$ e da hepatite $\mathrm{C}$, além de outros que possuem a mesma via de transmissão, como Leptospira interrogans, arbovírus, Brucella sp., Tripanossoma cruzi. Estima-se que nos países desenvolvidos o risco de contrair hepatite $B$, seja de 3 a 6 vezes maior entre trabalhadores da saúde do que entre a população em geral, sendo que nos países em desenvolvimento o risco é de 6 a 18 vezes maior. Por causa da hepatite $B$, a cada ano entre 200 e 300 trabalhadores perdem seus fígados $^{(8)}$. Mesmo o HIV, cujo risco de transmissão ocupacional é de apenas $0,3 \%$ em acidentes percutâneos, provocou infecções em 57 trabalhadores de saúde nos Estados Unidos em 2001 ${ }^{(9)}$.

No caso de exposição ao vírus da aids, a quimioprofilaxia é feita quando o paciente fonte é soropositivo para o HIV. Ela deve ter início, de preferência, nas primeiras 24 horas do acidente, não devendo ultrapassar 72 horas do ocorrido. Os exames laboratoriais devem ser feitos no momento do acidente, após seis semanas, três meses, seis e 12 meses depois do acidente ${ }^{(10)}$. É muito raro não apresentar sintomas como disenteria, febre alta e linfadenopatia após a soroconversão. 
A vacina contra hepatite B tem eficácia entre 90 e 95\%. No caso de pessoas que não completaram o esquema de três doses da vacina ou que não conseguiram resposta vacinal mesmo após seis doses, a quimioprofilaxia é feita com imunoglobulina hiperimune contra hepatite B (IGHAHB), que produz imunidade até seis meses depois da exposição ${ }^{(10)}$. Os profissionais imunizados não necessitam fazer seguimento laboratorial.

Contra a hepatite $C$ não existe quimioprofilaxia, o acompanhamento do funcionário é realizado através da dosagem das transaminases, sorologia para detecção de anticorpos anti-HCV no momento e seis meses após o acidente, sendo confirmados pelo achado de RNA viral. O único método eficaz para prevenir a infecção pelo vírus da hepatite $C$ é evitar a exposição percutânea ${ }^{(10)}$.

Dentre os trabalhadores de saúde, os que têm maior probabilidade de acidentes são os de Enfermagem, especialmente os de nível médio, que são os que prestam assistência direta ao cliente. Principalmente os que trabalham em hospital, por este ser um ambiente insalubre em que se aglomeram pacientes com várias patologias transmissíveis, além de ser um local em que se lida cotidianamente com a morte e sobrecarga de trabalho.

Em relação à saúde ocupacional, a Norma Operacional Básica do SUS 01/96 (NOB-SUS 01/96) define que um dos campos de atenção do SUS é o das intervenções ambientais, incluindo as relações e as condições de ambiente e trabalho ${ }^{(1)}$. O Manual para Organização da Atenção Básica no SUS tem como atribuições do SUS em relação à saúde do trabalhador "divulgação de informações e orientações educativas [...] visando a redução da morbimortalidade por acidentes e doenças do trabalho", além de "assistência básica aos acidentados e portadores de doenças relacionadas ao trabalho e notificação dos agravos e riscos relacionados ao trabalho". Isso está bem demarcado na Lei Orgânica do SUS. Nela, o parágrafo terceiro descreve que a saúde do trabalhador dar-seá por meio de atividades de vigilância epidemiológica e vigilância sanitária, tendo em vista a proteção e a promoção da saúde, além de recuperação e reabilitação, se for o caso $^{(2)}$.

Considerando o exposto anteriormente, é importante investigar os acidentes de trabalho entre a equipe de Enfermagem bem como propor medidas preventivas. Portanto os objetivos deste trabalho são: caracterizar os acidentes de trabalho ocorridos entre profissionais de saúde, analisar a freqüência dos acidentes de trabalho na equipe de Enfermagem notificados na Comunicação de Acidentes de Trabalho e identificar quais os fatores contribuintes para a ocorrência de acidentes entre os trabalhadores de Enfermagem.

\section{MATERIAIS E MÉTODOS}

Trata-se de um estudo documental exploratório, realizado durante o mês de abril de 2005 junto aos registros de notificação de acidentes por objetos cortantes da Comissão de Controle de Infecção Hospitalar (CCIH). A Comunicação de Acidente de Trabalho (CAT) não foi o documento de escolha nesta pesquisa pois, segundo enfermeiras da $\mathrm{CCIH}$, é preenchida em outro hospital de referência. Compuseram esta amostra tanto as fichas de estagiários de nível médio e superior como as de profissionais de carteira assinada.

As fichas estudadas registravam acidentes ocorridos entre março de 2003 e abril de 2005. Das 65 fichas inicialmente analisadas 23 apresentavam inconsistências (ausência de preenchimento dos campos data, hora e partes do corpo atingidas) que poderiam prejudicar a análise da relação entre o acidente e a complexidade do procedimento executado, portanto foram excluídas.

Os dados estão agrupados em tabelas e quadros e sua análise foi procedida com o apoio do programa estatístico EPInfo versão 3.2.2 utilizando estatísticas descritivas como freqüência absoluta, medida de tendência central e percentual, além de estatísticas inferenciais, para identificar associação entre as variáveis.

Para contemplar os aspectos referentes à Resolução 196/96 do Ministério da Saúde foi autorizada a realização deste estudo pelo diretor da instituição por meio de ofício protocolado e o projeto foi aprovado pelo Comitê de Ética em Pesquisa (COMEPE) da Universidade Federal do Ceará (UFC).

\section{RESULTADOS E DISCUSSÃO}

Das 42 fichas que compuseram a amostra, em $54,8 \%$ dos acidentes os auxiliares de Enfermagem estavam envolvidos, resultado similar ao de outras pesquisas, em que até $48 \%{ }^{(11)}$ das amostras eram compostas por profissionais desta categoria. Estudiosos $^{(12)}$ argumentam que os auxiliares são a 
categoria mais numerosa dentre os profissionais de Enfermagem e são os que prestam assistência direta ao paciente, principalmente administração de medicação injetável, o que, devido sua natureza invasiva, predispõe à ocorrência de acidentes. As enfermeiras e os técnicos em Enfermagem tiveram mesmo percentual de acidentes, com 11,9\% cada um. $\mathrm{O}$ que difere de um estudo anterior ${ }^{(11)}$, em que as enfermeiras foram a segunda categoria mais atingida por acidentes seguidas dos técnicos em Enfermagem.

O funcionário acidentado manuseava o instrumento causador do agravo em 85\% dos casos. Outra pesquisa $^{(6)}$ encontrou que $73 \%$ das exposições ocorreram em decorrência do descuido ou desatenção na execução das tarefas. Em outro estudo ${ }^{(12)}$ foi identificado que os itens desatenção ou descuido somaram $74,7 \%$ do total de acidentes. É possível que o percentual elevado encontrado no presente estudo possa ter sido causado também por descuido. Todavia, é necessário atentar para o fato de que existem outras possíveis explicações que não foram investigadas aqui.

Em um dos estudos ${ }^{(6)}$, a situação sorológica do paciente-fonte era conhecida em 52\% dos casos, o que se assemelha a este, em que a situação do paciente-fonte era conhecida em $66,7 \%$. A diferença no percentual pode ter sido influenciada pelo tamanho reduzido da amostra. Contudo, em 33,3\% dos acidentes não foi possível investigar o paciente-fonte. Isso dificulta a busca pela quimioprofilaxia adequada bem como o acompanhamento do profissional, pois se este desenvolver alguma doença infecto-contagiosa, não será possível provar se está relacionada ao trabalho.

Dos funcionários acidentados, 48,6\% apresentava anticorpos anti-HBV. Considerando que a vacina contra hepatite B tem eficácia entre 90 e $95 \%$, e é considerada segura ${ }^{(10)}$. É possível também que pessoas soropositivas apresentem anticorpos devido à exposição anterior ao patógeno, esta porcentagem é baixa. Outras pesquisas têm mostrado valores mais elevados. Há uma investigação na qual $60,98 \%$ dos acidentados havia se vacinado contra hepatite $\mathrm{B}^{(6)}$. Em outra foi encontrado um índice de vacinação de $69 \%^{(13)}$.

Em relação ao HIV, comprovadamente não houve soroconversão em 59,4\% dos casos, em 6\% houve conversão, em 34,4\% o status sorológico é desconhecido.

Em relação ao local do acidente, os resultados são bastante semelhantes aos de outras pesquisas. $\mathrm{Na}$ maioria das pesquisas o quarto do paciente foi o local em que aconteceu grande parte dos acidentes ${ }^{(6,14-15)}$, dados parecidos com os desta pesquisa, em que 52,4\% do total de acidentes notificados ocorreram no quarto do paciente. O segundo local mais freqüente, com 21,4\% do total de acidentes, foi a sala de operação, similar a resultados encontrados por outro pesquisador ${ }^{(6)}$. Entretanto, esse mesmo autor refere que a UTI aparece com quase a mesma quantidade de acidentes, chegando a $8,11 \%$. De fato, causa estranheza a UTI não aparecer entre os locais mais freqüentes de ocorrência de acidentes, já que é uma área crítica do hospital em que se realizam muitos procedimentos invasivos, como aspiração orotraqueal, coleta de sangue arterial, banho no leito, além de reanimação cárdio-respiratória.

Como é demonstrado em outro estudo, $10 \%$ e $7 \%$ dos acidentes ocorreram no decorrer de aspiração orotraqueal e coleta de sangue arterial(11), respectivamente. No presente estudo, os procedimentos em que os profissionais mais comumente se acidentaram foram: injeção intramuscular ou subcutânea, aspiração e coleta de sangue. Embora a literatura apresente como um dos procedimentos que envolvem acidentes o ato de desconectar dispositivos intravenosos, no presente estudo não foram identificados registros de acidentes relacionados a tal situação. Os estudos mostram um percentual que varia de $2,5 \%$ até $20 \%$ do total de acidentes com aqueles dispositivos ${ }^{(13-14)}$.

No que se refere à finalidade do procedimento que causou o acidente, 35,7\% aconteceram ao realizar injeção intramuscular ou subcutânea, fato corroborado pelo resultado de outros pesquisadores ${ }^{(18)}$ que identificaram que perfurações durante injeção subcutânea e durante injeção intramuscular somaram $21,27 \%$. Neste estudo a manipulação de vias intravenosas, somando coleta de sangue, conexão de soro ou para início de uma via intravenosa, foi responsável por 23,8\% dos acidentes, resultado que apresenta números maiores que estudos similares ${ }^{(11)}$, nos quais $10 \%$ dos acidentes estiveram relacionados com manuseio de cateter e $7 \%$ com coleta de sangue arterial. Por outro lado, em outra referência consultada $^{(18)}$, as perfurações durante medicação intravenosa e durante soroterapia somaram 53,18\% do total.

Esta pesquisa também apresenta disparidades no que se refere a acidentes durante o descarte do objeto. Os acidentes causados nessa ocasião somaram apenas 2,5\%, enquanto que em outra o valor chegou a $20 \%$ no grupo controle e $18 \%$ no grupo 
experimental $^{(13)}$. Em Siqueira ${ }^{(6)}$ a percentagem foi menor, com 4,73\% de profissionais acidentados ao descartar objetos pérfuro-cortantes. As causas de acidentes nessa ocasião podem ser dividas ao dispositivo de descarte inadequado ou preenchido além $\operatorname{dos}_{3}^{2} /$ da capacidade $^{(4)}$. Muitos hospitais utilizam caixas de medicamento ou caixas de papelão para descartar os pérfuro-cortantes e não respeitam o limite, por isso muitas agulhas e outros pérfuro-cortantes ficam expostos, sujeitando trabalhadores ao risco de se acidentarem ao descartar algum objeto.

O objeto estava visivelmente contaminado com sangue ou outras matérias orgânicas em 61,5\% dos casos. Em 28,2\% dos acidentes o instrumento causador do acidente já fora utilizado no paciente, mas não apresentava contaminação visível. Os dados levantados por Heinrich ${ }^{(17)}$ mostram que parcela significativa dos acidentes ocorre após o uso do objeto. Este autor identificou que $50 \%$ dos acidentes ocorrem entre o término do procedimento e o descarte do dispositivo.

Agulhas de seringa foram os objetos que mais causaram acidentes, com 51,3\% do total. Em seguida constam os catéteres de acesso periférico (25,6\%). Dados similares a outro trabalho, em que dos 67 profissionais acidentados, 35 (52,2\%) tiveram agulha de seringa como objeto causador, seguido por 19 $(28,3 \%)$ catéteres de acesso periférico ${ }^{(12)}$. Já em outro estudo foi encontrado um percentual de $40 \%$ dos acidentes causados por agulhas ${ }^{(11)}$, enquanto em Ribeiro $^{(15)}$ as agulhas se apresentaram em $88,73 \%$ dos acidentes.

Nos Estados Unidos ocorrem cerca de 384 mil exposições percutâneas por ano, sendo que, destas, 236 mil são causadas por agulhas ocas. Acidentes com agulhas ocas oferecem maior risco de contaminação do que com agulhas de sutura, já que as agulhas de sutura contêm um volume menor de sangue. Vários estudos mostram a eficiência dos dispositivos seguros quando é mostrada uma estimativa de prevenção de 69 mil acidentes caso fossem utilizados dispositivos seguros. Entretanto, esses dispositivos oferecem limitações em relação ao preço e ao uso em determinadas especialidades, como Odontologia e Pediatria ${ }^{(17)}$.

$\mathrm{O}$ ato de reencapar agulhas é um grande problema entre os profissionais de Enfermagem, sejam de nível médio ou superior. Os dados de outras pesquisas oscilam entre $15,9 \%^{(16)}$ e $24 \%^{(14)}$, neste mesmo estudo $74,2 \%$ das agulhas envolvidas em acidentes percutâneos já haviam sido utilizadas no paciente. Em Siqueira $^{(6)}$ o reencape de agulhas foi responsável por 14,86\% dos acidentes, representando a terceira causa de acidentes em seu estudo. O reencape é identificado como causa preponderante de acidentes entre auxiliares e técnicos em Enfermagem. Há alguns anos essa prática foi desaconselhada e substituída pelas precauções padronizadas, na qual uma das metas é a prevenção dos acidentes com agulhas para evitar a infecção por patógenos transmitidos pelo sangue. Entretanto, entre as causas do hábito de reencapar agulhas, está o fato de as caixas de descarte estarem distante da área de manipulação de pérfuro-cortantes ${ }^{(4)}$.

Na maioria dos casos o ferimento causado pelo acidente foi de superficial a moderado, ambos em $48,6 \%$ do total de casos notificados, havendo apenas 2,9\% de ferimentos considerados severos, de acordo com a classificação existente na própria ficha de notificação. É importante ressaltar que, na mesma, não havia qualquer orientação sobre tal classificação.

Em 65\% dos acidentes investigados os dedos foram os locais atingidos. Somado com as mãos, que representam $12,5 \%$, os membros superiores representam $77,5 \%$ do total, sendo as partes do corpo mais atingidas. Em 2004 foi mostrado que 56,4\% das exposições percutâneas ocorreram nas mãos ${ }^{(8)}$. No estudo de Siqueira ${ }^{(6)}$ os membros superiores foram os mais atingidos em 93,24\% dos casos.

\section{CONCLUSÃO}

Acidentes de trabalho por objeto pérfurocortantes entre os profissionais de Enfermagem é um assunto que merece atenção, pois envolve o risco de infecção por patógenos sangüíneos.

Os auxiliares de Enfermagem foram os que mais sofreram acidentes nesse período, com mais de 50\% de freqüência nessa categoria. A ocasião em que mais aconteceram acidentes foi ao reencapar agulhas. Este é um problema sério na categoria, porém é preciso lembrar que nem sempre os dispositivos de descarte estão bem distribuídos, na maioria das vezes se concentram no posto de Enfermagem, portanto, para não expor outros com material contaminado os profissionais preferem reencapar. $\mathrm{O}$ ato de reencapar agulhas não é apenas um costume, é também um problema gerencial que envolve as condições de trabalho da equipe de Enfermagem.

O quarto é o local em que os acidentes ocorrem com mais freqüência, representando 52,4\% do total. Isso reforça a hipótese de que as caixas de descarte 
estão mal distribuídas e o profissional só pode rejeitar os pérfuro-cortantes no posto de Enfermagem. O segundo local mais freqüente foi a sala de operação, com $21,4 \%$.

As agulhas apareceram como o principal instrumento envolvido na causa de acidentes, em geral utilizadas para injeção intramuscular ou subcutânea. Em segundo lugar está a exposição a cateteres intravenosos previamente utilizados nos pacientes.

As partes do corpo mais atingidas foram os membros superiores (mãos e dedos), por estas serem as mais utilizadas na execução das tarefas.

A educação em serviço é indispensável para que o trabalhador veja a importância das precauções padronizadas, entre as quais está incluída a prevenção de acidentes com pérfuro-cortantes e adoção de práticas seguras. Entretanto, é necessário que a Comissão Interna de Prevenção de Acidentes (CIPA) e o Serviço de Saúde e Segurança do Trabalhador implementem medidas que tornem as condições de trabalho mais seguras, o que contribui para a redução dos acidentes.

Possivelmente muitos acidentes não foram notificados, já que em locais como a UTI se lida com pacientes críticos, realizando procedimentos invasivos e esse setor não apareceu nas fichas de notificação. Isso faz notar a burocracia envolvida no processo, que dificulta a busca do profissional pelo atendimento em caso de exposição ocupacional. È importante lembrar que muitos profissionais ignoram a necessidade de relato. Também é preciso salientar que muitas fichas continham dados incompletos, o que dificulta analisar a dimensão do problema. Além disso, pode-se sugerir a mudança de alguns itens, como, por exemplo, o que trata da ocasião do acidente e o da presença de antiHIV, que podem induzir erro ao preencher.

\section{REFERÊNCIAS}

1. Costa RCR. Descentralização, financiamento e regulação: a reforma do sistema público de saúde no Brasil durante a década de 1990. Rev. Sociol. Polit [periódico na Internet].2002 Jun [acesso em 2004 Ago 26]18:1-52. Disponível em www.scielo.br.

2. Brasil, Ministério da Saúde. Recomendações para atendimento e acompanhamento de exposição ocupacional a material biológico: HIV e hepatites B e C. [acesso em 2005 Mai 26] Disponível em <http:// www.saude.gov.br/bvs>.

3. Posso MBS, Sant'Anna ALGG, Giaretta VM A, Chagas
LR, Cardoso PR. Biossegurança: o vivenciar de sua interdisciplinaridade. Prática hospitalar [periódico na Internet].2004 Jul/Ago [acesso em 2005 Set 19]34(6):1547. Disponível em scholar.google.com.br.

4. Marziale MHP, Rodrigues CM. A produção científica sobre os acidentes de trabalho com material perfurocortante entre trabalhadores de enfermagem. Rev Latino-Am Enferm [periódico na Internet]. 2002 Jul/Ago [acesso em 2004 Set 1]10(4):571-7. Disponível em www.scielo.br.

5. Centers For Disease Control And Prevention. Updated U.S. Public Health Service Guidelines for the Management of Occupational Exposures to HBV, HCV, and HIV and Recommendations for Postexposure Prophylaxis. MMWR 2001; 50. [acesso em 2004 Set 1]. Disponível em www.cdc.gov.

6. Siqueira WKAD. Acidentes ocupacionais no ambiente hospitalar: riscos à saúde dos profissionais [monografia]. Fortaleza (CE): Universidade Estadual do Ceará-UECE, 2003.

7. Costa MAF, Costa MFB. Biossegurança: elo estratégico de SST. Revista CIPA [on line]. 2002 Jan; 253. [acesso em 2004 Mai 24]. Disponível em www.fiocruz.br.

8. Kosgeroglu N, Ayranci U, Vardareli E, Dincer S. Occupational exposure to hepatitis infection among Turkish nurses: frequency of needle exposure, sharps injuries and vaccination. Epidemiology and Infection. 2004 fev; 132(1): 27-33. [acesso em 2005 Abr 29]. Disponível em www.periodicos-capes.gov.br.

9. Centers For Disease Control And Prevention. Surveillance of Healthcare Personnel with HIV/AIDS, as of December 2002. $2002 \mathrm{dez}$. [acesso em 2004 Set 10]. Disponível em www.cdc.gov/ncidod/hip/blood/ hivpersonnel.htm.

10. Brasil, Ministério da Saúde. Secretaria de Atenção à Saúde. Departamento de Ações Programáticas Estratégicas. Legislação em saúde: caderno de legislação em saúde do trabalhador. $2^{\text {a }}$. ed. rev. e ampl. - Brasília: Ministério da Saúde, 2005. [acesso em 2005 Mai 26]. Disponível em www.saude.gov.br/bvs.

11. Nishide VM, Benatti MCC, Alexandre NMC. Ocorrência de acidente do trabalho em uma unidade de terapia intensiva. Rev Latino-Am Enferm [periódico na Internet].2004 Mar/Abr [acesso em 2004 Set 1]12( 2): 204-11. Disponível em www.scielo.br

12. Pereira ACM, Silva AR, Rocha CF, Cordeiro IS, Lopes 
CM. Work accidents with needles and other sharp medical devices in the nursing team at public hospitals - Rio Branco, Acre-Brazil. Online Braz J Nurs [periódico na Internet]. 2004 Dez [acesso em 2005 Out 19]3(3). Disponível em: www.uff.br.

13. Wang H, Fennie K, He G, Burgess J, Williams AB. A training programme for prevention of occupational exposure to bloodborne pathogens: impact on knowledge, behaviour and incidence of needle stick injuries among student nurses in Changsha, People's Republic of China. J Adv Nursing [periódico na internet].2003 [acesso em 2005 Abr 29]41(2):187-194. Disponível em: www.periodicos-capes.gov.br.

14. Guo YL, Shiao J, Chuang JC, Huang, KY. Needlestick and sharps injuries among health-care workers in Taiwan. Epidemiology and Infection [periódico na Internet].1999 Abr [acesso em 2005 Abr 29]122(2):259265. Disponível em www.periodicos-capes.gov.br.

15. Ribeiro EJG. Estudo de acidentes de trabalho com trabalhadores de Enfermagem de um hospital-escola do Distrito Federal. [dissertação]. Brasília (DF): Universidade de Brasília-UnB [periódico na Internet], 2004. [acesso em 2005 Mar 29]. Resumo disponível em: www.bireme.br.

16. Brevidelli MM, Cianciarullo TI. Análise dos acidentes com agulhas em um hospital universitário: situações de ocorrência e tendências. Rev Latino-Am Enferm [periódico na Internet].2002 Nov/Dez [acesso em 2004 Set 1]10(6):780-6. Disponível em www.scielo.br.

17. Heinrich J. Occupational safety: selected cost and benefit implications of needlestick prevention devices for hospitals. Washington, DC. [periódico na Internet].2000. [acesso em 2004 Set 9] Disponível em www.osha-slc.gov.

18. Marziale MHP, Nishimura KYN, Ferreira MM. Riscos de contaminação ocasionados por acidentes de trabalho com material pérfuro-cortante entre trabalhadores de Enfermagem. Rev Latino-Am Enferm [periódico na Internet].2004 Jan/Fev [acesso em 2005 Ago 25]12(1): 36-42. Disponível em: www.scielo.br. 